Leah Reever, ${ }^{1}$ Melissa Cater ${ }^{2}$ and Shannon M. Coleman ${ }^{3^{*}}$

1 Dept of Food Science and Human Nutrition, lowa State University, 220 MacKay Hall, 2302 Osborn Drive, Ames, IA 50011-1078, USA

2Dept. of Agriculture and Extension Education and Evaluation, Louisiana State University, JC Miller Hall, Room 125, 110 LSU Union Square, Baton Rouge, LA 70803, USA

lowa State University, Dept. of Food Science and

Human Nutrition, 2312 Food Sciences Bldg., 536

Farm House Lane, Ames, IA 50011-1054, USA
PEER-REVIEWED ARTICLE

Food Protection Trends, Vol. 41, No. 4, p. 389-399 Copyright $^{\oplus}$ 2021, International Association for Food Protection 2900 100th Street, Suite 309, Des Moines, IA 50322-3855, USA

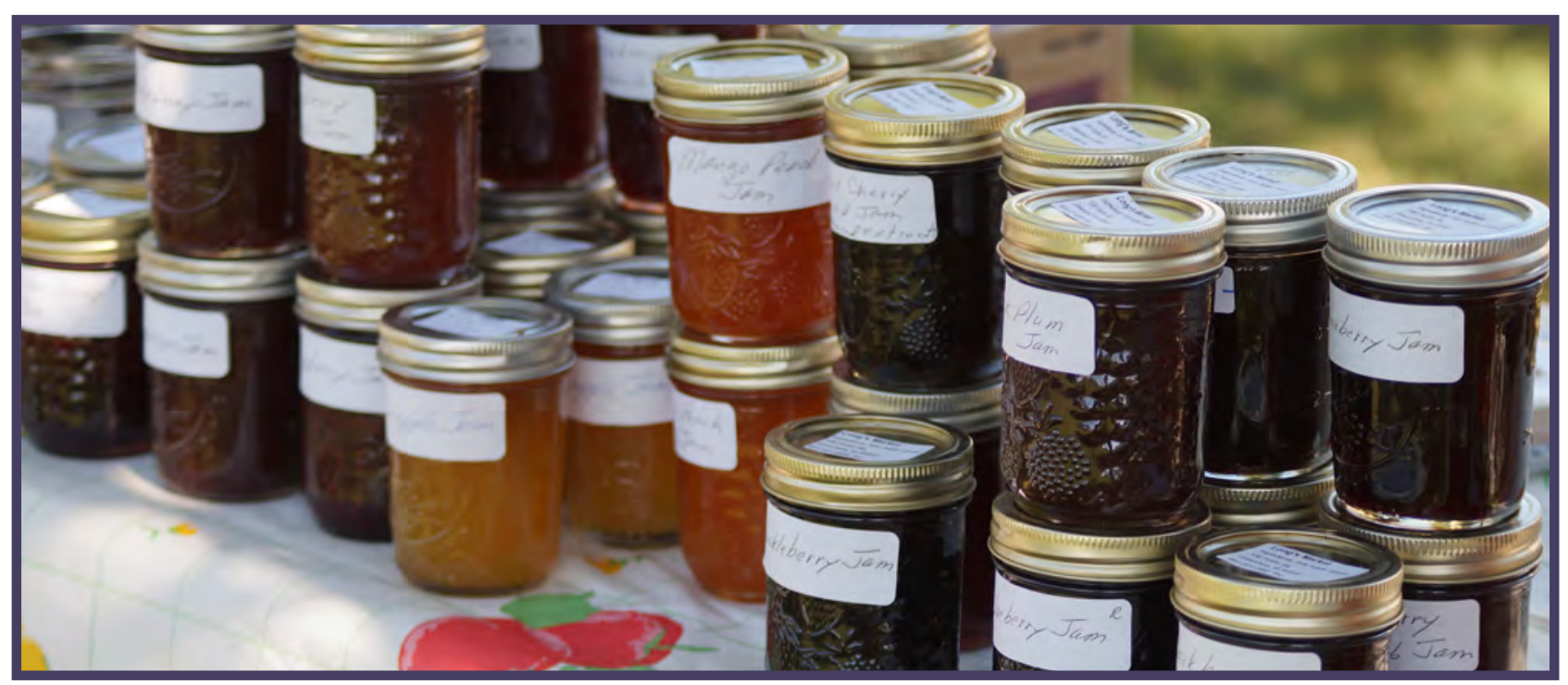

\title{
Assessing Short- and Long-term Food Safety Attitude and Behavior of Home-based Food Operators
}

\section{ABSTRACT}

Farmers' markets have become popular places for consumers to get a variety of other foods. However, confusion around state-specific food safety led to vendors being unclear about requirements. A needs assessment was distributed to vendors to determine the need for a training program addressing state-specific safety regulations. A State of lowa food regulations-specific food safety intervention was developed for home-based food operators about food safety practices applicable to the home kitchen, production, and point-of-sale. The objective of this study was to assess the changes in participants' attitudes and behavior toward food safety practices using the seven constructs from the Theory of Planned Behavior. Participants were asked to complete a pretest, a posttest, and a 6-to 8-week follow-up evaluation. Results of the assessment show that participants had a high mean response to the constructs, with all questions except attitude having a mean of 5 or higher and attitude having a mean of 4 or higher at all testing times. Participants' responses became slightly more positive between the pre and post survey but returned to levels close to the initial responses 6 to 8 weeks following the training program. The evaluation indicates a need to focus on participants' long-term attitude and behavioral changes within all constructs measured in training program.

\section{INTRODUCTION}

The U.S. Department of Agriculture $(29,30)$ reported 8,268 farmers' market locations in the United States, indicating increased consumer interest in local foods nationally. The Iowa Department of Agriculture and Land Stewardship reported that around 200 farmers' markets provide local fresh products to Iowans (13). One product type of concern at the market is prepared foods because most vendors of these foods are exempt from food safety regulations. The exemptions regulations consider the type of products being sold and the business size. An example of the vendors exempt from food safety regulations in Iowa are home-based food operators.

Two types of home-based food operators area recognized in Iowa: home bakers and exempt home food operators. 
Home bakers prepare nonperishable and perishable baked goods in their residences to be consumed elsewhere (15). The Iowa regulations allow for home baker residences to be licensed and inspected by state health inspectors. Producers are often confused that these vendors are allowed to sell only baked goods. The State of Iowa defines baked goods as "breads, cakes, doughnuts, pastries, buns, rolls, cookies, biscuits, and pies (except meat pies)" (16).

In contrast, exempt home food operators in Iowa are mostly unregulated. These vendors can make and sell various shelf-stable food products from only their homes and farmers' markets (14). These products include fresh fruits and vegetables, fruit preserves, honey, fresh shell eggs, nonperishable baked goods, dry mixes, and candy (14). A primary concern and knowledge issue for vendors is that many consumers are unaware of whether their final products are considered perishable $(3,18)$.

The risks of possible foodborne illness at farmers' markets are a concern because products sold have been linked to various outbreaks and recalls. Fresh produce sold at these markets, such as shelled peas, cantaloupes, and fresh strawberries, have been a source of foodborne illness (19, 31). Outbreaks also have been linked to ingredients for baked goods and perishable prepared foods (4, 6-8). The 2019 outbreak of E. coli O26 infection was linked flour distributed in Iowa and placed many home bakers at risk for a possible outbreak (5).

Home kitchen spaces used to prepare these products have been linked to foodborne illness due to improper handling, hand washing, and cleaning and sanitizing of food contact surfaces and kitchen equipment (2). Because of these foodborne illness risks and the farmers' market environment, farmers' market vendors should have specific training in food safety behaviors and practices (22). In Iowa, education concerning Iowa regulations is needed for home-based food operators. Various training programs and resources are available to those interested in home-based production and home-based preserving in the surrounding states (28-31); however, these regulations tend to contradict Iowa's regulations. A lack of consumer knowledge of food safety and lack of food-handler knowledge impact practices at farmers' markets (22, 32, 33). Researchers have recommended manager and vendor training programs focused on food safety behavior at farmers' markets $(11,27,32)$. Market managers often do not have set food safety standards regarding hand washing or sanitation of vendor spaces (12). Although knowledge is essential for food safety, it cannot solely influence food handlers' attitudes and behaviors $(9,24)$.

The Theory of Planned Behavior can be used to determine a person's intention to behave a certain way by looking at the person's attitude toward the behavior, personal control over the behavior, and social pressure to conform by performing a behavior (1). As stated earlier, knowledge does not always lead to a change in attitude and behavior, so a posttraining evaluation can be used to measure intention, attitude, and behavior. The theory includes constructs that allow researchers to determine the effect the training program had on the participants. Studies indicate that predicting food handlers' intentions and understanding of perceived behavioral control affect participants' behavior more than other factors $(23,26,28)$. Use of the theory can help researchers understand changes in participants' attitudes and the effects of training programs on participants' attitudes and behaviors.

When food handlers' attitudes do not change, proper food-handling practices will not be used. The overall goal of this project was to provide participants with a specific training program focused on state food regulations and to use the seven constructs from the Theory of Planned Behavior to assess the changes in participants' attitudes and behaviors regarding food safety practices.

\section{MATERIALS AND METHODS}

\section{Program design and development}

Prior to the development of a food safety training program, researchers administered a knowledge assessment (see Appendix for full survey) to participants who were interested in becoming or currently were home bakers and exempt home food operators (10). Researchers set the threshold for needing a training program at a mean of $75 \%$ correct responses, the standard also required to pass the National Restaurant Association's ServeSafe test. The needs assessment (Table 1) indicated that the average food safety knowledge score for all participants was below the threshold of $75 \%$. The assessment also identified key areas in food safety and Iowa law that should be covered in the food safety training program. The areas covered include food safety basics, Iowa laws and policies, and application of both food safety and Iowa law to the producer's own operations.

A lecture course was developed, which included a PowerPoint (Microsoft, Redmond, WA) presentation, interactive activities, discussions, and question-and-answer activities throughout the lecture. Chapters developed and covered in the lecture are shown in Table 2. Chapters were developed using resources from the National Restaurant Association ServSafe program, Iowa State University Extension and Outreach, the U.S. Food and Drug Administration, the U.S. Department of Agriculture, the Iowa Department of Inspections and Appeals, and the Iowa Department of Agriculture and Land Stewardship. At completion of the training program, participants received a certificate of completion but were not certified in any recognized program.

Bloom's taxonomy was used to develop the learning objectives and activities for the training program (17). Researchers focused on the first three levels: remembering, understanding, and applying concepts taught during the program. The fourth level, analyzing, was also part of some group discussions but was not frequently incorporated into the written learning objectives. The researchers focused on 
TABLE 1. Means \pm standard deviations of correct food safety responses (\%) and attitude answers (Likert scale 1-5) based on the producers' stage of change

\begin{tabular}{c|c|c} 
Stage of Change & Food Safety Responses $(\%)$ & Confidence Responses (Likert Scale) \\
\hline Contemplation $^{\mathrm{x}}$ & $77.63 \pm 14.18$ & $4.07 \pm .737^{\mathrm{a}}$ \\
\hline Preparation $^{\mathrm{a}}$ & $79.55 \pm 11.56$ & $4.15 \pm .614^{\mathrm{ab}}$ \\
\hline Action $^{z}$ & $70.31 \pm 13.05$ & $4.52 \pm .666^{\mathrm{b}}$ \\
\hline Total & $73.4 \pm 13.57$ & $4.36 \pm .700$ \\
\hline
\end{tabular}

${ }^{\mathrm{x}}$ Means of 19 participants, ${ }^{\mathrm{y}}$ Means of 11 participants, ${ }^{\mathrm{z}}$ Means of 48 participants

${ }^{a-b}$ Means separated by different superscripts are significantly different, $P<0.05$

these levels throughout the program due to the applicability or goal of the program and the program style - a 1-day workshop rather than a long-term or continuing course. The first Bloom's taxonomy level was remembering or memorization. The researchers found it to be critical that participants were able to "identify" and "recall" the information that was presented to them during the training program. For example, the researchers found it important for the participants to recall what products each group of producers could legally make. The next level, understanding, was also important for the participants. The researchers wanted them to not only recall what they could make but also to understand why they could make it and why it was legal. For example, a product is legal to sell when it meets the definition of a food that does not require time-temperature control for safety (TCS). The researchers wanted participants to understand why this difference is important and to be able to apply their understanding to their operations. For vendors who made products that were not explicitly mentioned in the definition that they recalled, researchers wanted these vendors to take their understanding of non-TCS products and apply it to those products to determine whether the products could be legally sold.

Learning activities were also utilized to help participants recall, understand, and apply the information in the program. Turn-to-your-partner exercises were developed to challenge participants to not only recall information but apply the concepts to their operations. Questions were posed to participants that required them to think about what they had learned and apply that information to answer the questions. Participants were given time to think about a question individually, discuss their thoughts with a partner or small group, and then discuss the question with the entire group. Other learning activities, such as personal reflections and group discussions, were also used. An example of a group discussion learning activity was viewing a video on personal hygiene within a commercial food manufacturing plant. The participants were then asked to discuss aloud the differences that they observed between their home operation and the commercial food manufacturing plant. Participants also discussed how some of the things they observed in the plant would affect the food safety of the products in their operations. This learning activity was designed to help participants analyze how their home operations were different from commercial operations found across the United States.

\section{Program recruitment and dissemination}

The researchers worked with multiple organizations to assess interest in the training program and to recruit potential participants. Researchers presented at venues such as local farmers' market meetings, the Iowa Annual Farmers' Market Meeting, Iowa State University Extension and Outreach Nutrition and Wellness Specialist meetings, the Iowa Small Business Development Center, and the Iowa Center for Economic Success. Researchers also relied on state and local governments to disseminate information about the training program. The Iowa Department of Inspections and Appeals and the Iowa Department of Agriculture and Land Stewardship allowed researchers to use farmers' market databases and local inspectors to recruit potential participants.

\section{Program evaluation}

To measure the impact of the training program, the researchers developed an evaluation to measure seven constructs: (i) participants' attitudes, (ii) behaviors toward food ingredients, (iii) behaviors toward the preparation environment, (iv) behaviors toward personal hygiene, (v) intention to adopt the food safety practices, (vi) perceived behavioral control, and (vii) willingness to conform to social pressures related to food safety. Researchers also evaluated the training program by comparing three groups of participants that were matched by location. The Theory of Planned Behavior was selected as a model for the evaluation because of its applicability to food safety training programs and attitude and behavioral changes. Figure 1 shows the model that was developed by the researchers in applying the Theory of Planned Behavior to the food safety training program. 


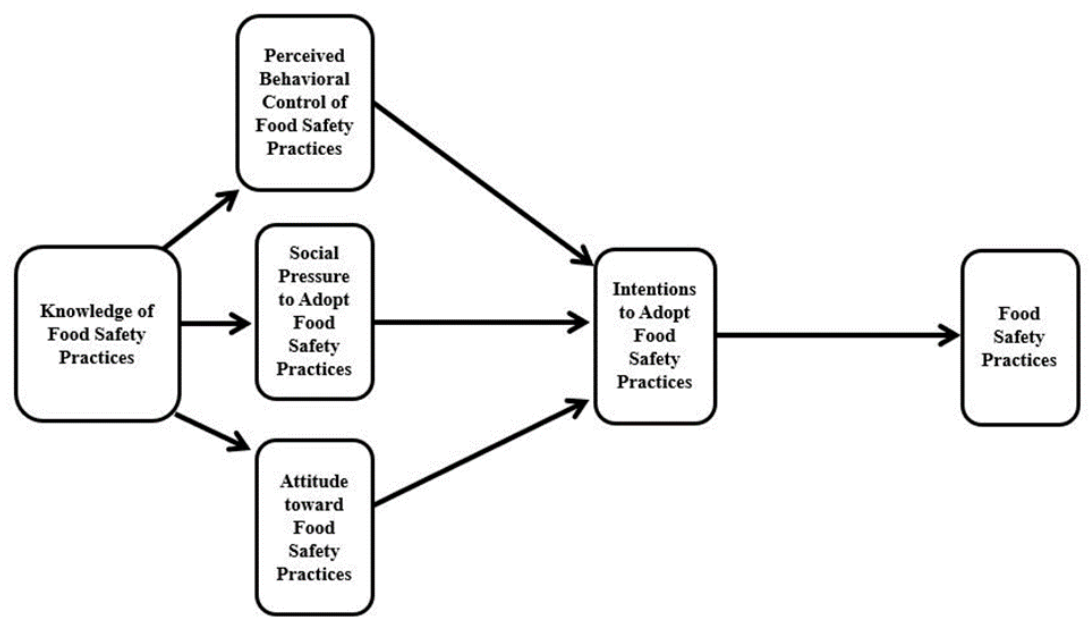

FIGURE 1 . Model of food safety training evaluation adapted from the Theory of Planned Behavior (1).

The researchers developed questions that focused on each aspect of the model. Questions included phrases or keywords that were linked back to the model to ensure that the researchers were assessing every area of the model (1). The knowledge portion of the model was delivered during the training program. The focus of this evaluation was to assess the impact of knowledge acquisition on the attitudes, intentions, and behaviors of the participants.

All evaluation questions focused on three general themes that were incorporated throughout the training program. Questions about attitudes toward food safety focused on personal choices in relation to food and ingredients, personal hygiene, and the preparation environment. Subjective norm questions addressed whether the participant agreed that coworkers, family, friends, health inspectors, and their customers expected them to use safe food practices. Perceived behavioral control questions evaluated participants' personal ability to follow in their personal operations certain food safety tasks that were recommended in the training program. The final section of the evaluation focused on the actual intention and behavior of the participants. Evaluation forms were given to participants after they signed a consent form before the training program (pretest), immediately after the program (posttest), and 6 to 8 weeks later (6- to 8-week follow-up evaluation). Participant age, gender, and race information was not collected. Demographic information was collected as part of a prior needs assessment, and the researchers' focus was on evaluating the participants' attitudes and behavior in relation to the training, not on the participants themselves. Participants used a Likert scale to respond to the questions in the survey, where 1 indicated strongly disagree, 2 indicated disagree, 3 indicated slightly disagree, 4 indicated slightly agree, 5 indicated agree, and 6 indicated strongly agree.

\section{Human subjects research approval}

The protocols for human subjects research for analysis was approved by the Institutional Review Board at Iowa State University - [18-014]. The surveys and questionnaires were reviewed by food safety experts at Iowa State University.

\section{Statistical analysis}

Answers were coded by response option, where $1=$ strongly disagree, 2 = disagree, 3 = slightly disagree, $4=$ slightly agree, 5 = agree, and $6=$ strongly agree. Data were analyzed and descriptive information about the constructs was summarized using means and standard deviations. An analysis of variance was used to determine whether differences existed among groups. Analyses were performed using SPSS version 25 (SPSS, IBM, Armonk, NY).

\section{RESULTS AND DISCUSSION}

Descriptive statistics for pretest, posttest, and 6- to 8-week follow-up are presented in Tables 2, 3, and 4, respectively. In all surveys (pretest, posttest, and follow-up), all constructs except for attitude had a mean of 5 or higher. The questions asked were within the constructs of behavior toward food ingredients, preparation environment, personal preparation, intention, perceived behavioral control, and social norms. Attitude scores for all surveys had a mean score of 4 or higher, indicating that participants had a slightly less positive attitude, responding to the attitude question as "slightly agree."

The results in Tables 3, 4, and 5 indicate that overall the participants had a high mean response to the constructs; all questions except those regarding attitude had a mean of 5 or higher, and attitude had a mean of 4 or higher at all testing times. Thus, participants had positive feelings about behaviors toward food ingredients, the preparation 
TABLE 2. Chapters and corresponding subject matter covered in the pilot food safety training for exempt home food operations and home bakeries in lowa

\begin{tabular}{c|l} 
Chapter Number & Subject Matter \\
\hline 1 & Iowa policies and regulations \\
\hline 2 & Food safety basics \\
\hline 3 & Foodborne pathogens \\
\hline 4 & Non-temperature and temperature control for safety \\
\hline 5 & Kitchen: production area safe food practices \\
\hline 6 & Preparation: safe food practices \\
\hline 7 & Sourcing ingredients, packaging, shelf life and point of sale: safe food practices
\end{tabular}

TABLE 3. Mean \pm Standard Deviation (scale 1-6) for seven constructs modeled after the Theory of Planned Behavior, used to evaluate participants prior (pre-test) to the food safety training

\begin{tabular}{c|c} 
Construct Evaluated & Mean \pm Standard Deviation \\
\hline Behaviors Towards Food Ingredients $(\mathrm{n}=49)$ & $5.66 \pm 0.70$ \\
\hline Behaviors Towards Preparation Environment $(\mathrm{n}=49)$ & $5.63 \pm 0.46$ \\
\hline Behaviors Towards Personal Preparation $(\mathrm{n}=49)$ & $5.49 \pm 0.75$ \\
\hline Intention $(\mathrm{n}=49)$ & $5.71 \pm 0.84$ \\
\hline Perceived Behavioral Control $(\mathrm{n}=49)$ & $5.40 \pm 0.52$ \\
\hline Social Norms $(\mathrm{n}=48)$ & $5.80 \pm 0.38$ \\
\hline Attitude $(\mathrm{n}=49)$ & $4.57 \pm 0.60$ \\
\hline
\end{tabular}

TABLE 4. Mean \pm Standard Deviation (scale 1-6) for seven constructs modeled after the Theory of Planned Behavior, used to evaluate participants immediately after (post-test) the food safety training ( $n=51$ )

\begin{tabular}{c|c} 
Construct Evaluated & Mean \pm Standard Deviation \\
\hline Behaviors Towards Food Ingredients & $5.91 \pm 0.22$ \\
\hline Behaviors Towards Preparation Environment & $5.84 \pm 0.34$ \\
\hline Behaviors Towards Personal Preparation & $5.76 \pm 0.52$ \\
\hline Intention & $5.81 \pm 0.63$ \\
\hline Perceived Behavioral Control & $5.71 \pm 0.43$ \\
\hline Social Norms & $5.91 \pm 0.24$ \\
\hline Attitude & $4.66 \pm 0.69$ \\
\hline
\end{tabular}


TABLE 5. Mean \pm Standard Deviation (scale 1-6) for seven constructs modeled after the Theory of Planned Behavior, used to evaluate participants 6-8 weeks after (6-8-week follow-up) the food safety training

\begin{tabular}{c|c} 
Construct Evaluated & Mean \pm Standard Deviation \\
\hline Behaviors Towards Food Ingredients $(\mathrm{n}=29)$ & $5.85 \pm 0.31$ \\
\hline Behaviors Towards Preparation Environment $(\mathrm{n}=28)$ & $5.70 \pm 0.42$ \\
\hline Behaviors Towards Personal Preparation $(\mathrm{n}=28)$ & $5.71 \pm 0.44$ \\
\hline Intention $(\mathrm{n}=28)$ & $5.84 \pm 0.36$ \\
\hline Perceived Behavioral Control $(\mathrm{n}=28)$ & $5.46 \pm 0.50$ \\
\hline Social Norms $(\mathrm{n}=28)$ & $5.75 \pm 0.37$ \\
\hline Attitude $(\mathrm{n}=28)$ & $4.39 \pm 0.48$ \\
\hline
\end{tabular}

\section{TABLE 6. Mean \pm Standard Deviation (scale 1-6) based on participant location (designated as group one) between pre-test and post-test within constructs of the evaluation, $P<0.05$}

\begin{tabular}{|c|c|c|}
\hline Construct Evaluated & Pre-test $(\mathrm{n}=17)$ & Post-test $(n=16)$ \\
\hline Behaviors Towards Food Ingredients & $5.79 \pm 0.31$ & $5.97 \pm 0.09$ \\
\hline Behaviors Towards Preparation Environment & $5.74 \pm 0.36$ & $5.95 \pm 0.14$ \\
\hline Behaviors Towards Personal Preparation & $5.55 \pm 0.49^{*}$ & $5.90 \pm 0.20^{*}$ \\
\hline Intention & $5.76 \pm 0.97$ & $6.00 \pm 0.00$ \\
\hline Perceived Behavioral Control & $5.58 \pm 0.43$ & $5.84 \pm 0.46$ \\
\hline Social Norms & $5.79 \pm 0.42$ & $6.00 \pm 0.00$ \\
\hline Attitude & $4.81 \pm 0.69$ & $4.85 \pm 0.91$ \\
\hline
\end{tabular}

$\left({ }^{*}\right)$ indicate significance at the 0.05 level

TABLE 7. Mean \pm Standard Deviation (scale 1-6) based on participant location (designated as group two) between pre-test and post-test, within constructs of the evaluation, $P<0.05$

\begin{tabular}{|c|c|c|}
\hline Construct Evaluated & Pre-test $(n=15)$ & Post-test $(n=16)$ \\
\hline Behaviors Towards Food Ingredients & $5.36 \pm 1.15$ & $5.84 \pm 0.31$ \\
\hline Behaviors Towards Preparation Environment & $5.47 \pm 0.62$ & $5.83 \pm 0.30$ \\
\hline Behaviors Towards Personal Preparation & $5.27 \pm 1.09$ & $5.69 \pm 0.48$ \\
\hline Intention & $5.81 \pm 0.39$ & $5.76 \pm 0.41$ \\
\hline Perceived Behavioral Control & $5.20 \pm 0.58$ & $5.52 \pm 0.52$ \\
\hline Social Norms & $5.76 \pm 0.41(\mathrm{n}=14)$ & $5.86 \pm 0.31$ \\
\hline Attitude & $4.40 \pm 0.43$ & $4.36 \pm 0.33$ \\
\hline
\end{tabular}


environment, personal preparation, intentions, perceived behavior control, social norms, and attitude. Between the pretest and posttest, mean scores increased across all constructs, although the increases were not significant.

Although the mean scores for the training session increased from pretest to posttest (Table 4), when the follow-up data were collected (Table 5), the responses returned to levels similar to those seen prior to the training session (Table 3) or to levels slightly lower than those at the posttest survey. No short- or long-term effects were observed. This finding might be explained by the strength of participants' attitudes. Maio and Haddock (20) discussed the effect of strength of an attitude on the longevity of that attitude. These authors stated that strong attitudes are "persistent over time, resistant to change, likely to influence information processing, and likely to predict behavior" (20). Throughout the evaluation, mean attitude responses averaged no higher than 4.66 (Table 6), indicating that although the attitudes were positive, they were not as strong as a mean response of 5.00 to 6.00 would have reflected. The strength of participants' attitudes or lack thereof may reflect why there was not a long-term effect on behaviors (20).

Participants were divided into groups based on the location where they attended the training session. The results in Table 6 are the mean \pm the standard deviation for group 1 responses between the pretest and posttest. For participants in group 1, no significant differences were found except for behaviors toward personal preparation between the pretest and posttest, $F=3.71$, dfbetween $=2, \mathrm{df}_{\text {within }}=40$. In this construct, between the pretest and posttest, group 1 participants' mean response increased by $0.35, P=0.03$. All other constructs for group 1 participants increased between the pretest and posttest, but the increases were not significant. Due to low response rates, no 6- to 8-week follow-up data were analyzed for variations between groups 1,2 , and 3 but were analyzed for all participants. The results in Table 5 are the mean responses within group 1 for all constructs and all testing times. A significant difference was found between the pretest and posttest scores within the construct of personal preparation behaviors, which are similar to personal hygiene behaviors. This significant difference in scores suggests that the training program had an immediate positive impact on participants' personal preparation behavior.

Results in Table 7 are the mean \pm the standard deviation for group 2 responses on the pretest and posttest. For participants in group 2, mean scores increased from pretest to the posttest; however, there were no significant differences between any testing time responses or constructs. The results in Table 7 indicate no significant differences in any of the constructs measured at any of the times for the participants in group 2. Responses within this group are like those of the other two groups; no significant differences were observed between the testing times. Thus, although the responses were positive (mean of 5 or higher and 4 or higher for attitude), no changes in the participants were noted from before the training session to immediately after the session.

Results in Table 8 are the mean \pm the standard deviation for group 3 responses between the pretest and posttest. Foe participants in group 3, significant differences in mean responses were found between the pretest and posttest and within the construct of perceived behavioral control, $F=3.87$, $\mathrm{dfbetween}=2, \mathrm{df}_{\text {within }}=46$. Scores in this construct increased by $0.38, P=0.03$. For all other constructs, scores were not significantly different between the pretest and posttest.

For participants in group 3 (Table 8), significant differences in responses were found between the pretest and posttest for perceived behavioral control, which indicates that participants felt more positive after the training session than before the training session about being able to achieve some food safety practices. Milton and Mullan (21) found a significant increase in perceived behavior control in the intervention group for intentions to prepare food hygienically (21). In previous studies, perceived behavioral control

\section{TABLE 8. Mean \pm Standard Deviation (scale 1-6) based on participant location (designated as group three) between pre-test and post-test, within constructs of the evaluation, $P<0.05$}

\begin{tabular}{|c|c|c|}
\hline Construct Evaluated & Pre-test $(n=15)$ & Post-test $(n=16)$ \\
\hline Behaviors Towards Food Ingredients & $5.78 \pm 0.34$ & $5.91 \pm 0.19$ \\
\hline Behaviors Towards Preparation Environment & $5.68 \pm 0.37$ & $5.76 \pm 0.47$ \\
\hline Behaviors Towards Personal Preparation & $5.63 \pm 0.60$ & $5.70 \pm 0.70$ \\
\hline Intention & $5.56 \pm 1.00$ & $5.69 \pm 0.95$ \\
\hline Perceived Behavioral Control & $5.39 \pm 0.52^{*}$ & $5.78 \pm 0.23^{*}$ \\
\hline Social Norms & $5.82 \pm 0.34$ & $5.87 \pm 0.28$ \\
\hline Attitude & $4.47 \pm 0.58$ & $4.74 \pm 0.65$ \\
\hline
\end{tabular}

$\left({ }^{*}\right)$ indicate significance at the 0.05 level 
TABLE 9. Mean \pm Standard Deviation (scale 1-6) based on all participant answers between pre-test, post-test, and 6-8-week follow-up, with in constructs of the evaluation, $\mathbf{P}<0.05$

\begin{tabular}{c|c|c|c} 
Construct Evaluated & Pre-test $(\mathbf{n}=\mathbf{4 9})$ & Post-test $(\mathbf{n}=\mathbf{5 1})$ & Follow-up $(\mathbf{n}=\mathbf{2 8})$ \\
\hline Behaviors Towards Food Ingredients & $5.66 \pm 0.70$ & $5.91 \pm 0.22$ & $5.85 \pm 0.31(\mathrm{n}=29)$ \\
\hline Behaviors Towards Preparation Environment & $5.63 \pm 0.46^{*}$ & $5.84 \pm 0.34^{*}$ & $5.70 \pm 0.42$ \\
\hline Behaviors Towards Personal Preparation & $5.49 \pm 0.75$ & $5.76 \pm 0.52$ & $5.71 \pm 0.44$ \\
\hline Intention & $5.71 \pm 0.84$ & $5.81 \pm 0.63$ & $5.84 \pm 0.36$ \\
\hline Perceived Behavioral Control & $5.40 \pm 0.52^{*}$ & $5.71 \pm 0.43^{*}$ & $5.46 \pm 0.50$ \\
\hline Social Norms & $5.80 \pm 0.39$ & $5.91 \pm 0.24$ & $5.75 \pm 0.37$ \\
\hline Attitude & $4.57 \pm 0.60(\mathrm{n}=48)$ & $4.66 \pm 0.69$ & $4.39 \pm 0.48$ \\
\hline
\end{tabular}

$\left({ }^{*}\right)$ indicate significance at the 0.05 level

played a key role in predicting food handlers' intentions and understanding of their effect on participants' behaviors (23, 26, 28). For example, participants in the present study were asked whether "using a three-compartment sink to wash, rinse, and sanitize my [their] dishes and utensils is possible for me [them] to do." Although some participants may have had a three-compartment sink, others may not, and an understanding of their control with regard to achieving this practice is important. Participants may have felt prior to the training session that use of a three-compartment sink was not possible for them due to space concerns or because their kitchens may have had only one or two sink compartments. However, after the training in which educators discussed alternative options to "create your own three-compartment sink," participants may have felt that using an alternative was something that they could achieve and control.

Results in Table 9 are the mean \pm standard deviation for all participant responses. Significant differences were observed between pretest and posttest within the constructs of behaviors toward the preparation environment $(F=3.45$, dfbetween $=2$, $\left.\mathrm{df}_{\text {within }}=125\right)$ and perceived behavioral control $(F=5.74$, $\left.\mathrm{dfbetween}=2, \mathrm{df}_{\text {within }}=125\right)$. Between the pretest and posttest, mean responses rose by $0.21(P=0.03)$ for behaviors toward the preparation environment and by $0.31(P=0.00)$ for perceived behavioral control. All other constructs and testing time responses were not significantly different.

For all participant responses (Table 9), significant differences were observed within the constructs of preparation environment and perceived behavioral control. Preparation environment refers to sanitizing, cleaning, using food grade materials, excluding pets, and the overall state of the kitchen where food is being prepared. The response differences again suggest that participants had an increase in positive responses to the construct after receiving the training. These results are not surprising because of the focus and amount of material presented to participants in these areas. Several chapters (modules) of the training program were dedicated to the proper methods for preparing the kitchen for making food. The training program identified practices within commercial and retail food manufacturing facilities that are difficult for home-based food operators to achieve in the home setting and provided alternatives or solutions for incorporating those same large-scale practices into the home operation, such as use of the three-compartment sink example.

However, no significant differences were found for the other constructs, and no differences were found between the 6- to 8-week follow-up and the pretest and posttest responses in the constructs for which significant differences were found (Table 9). This finding suggests that the long-term positive outlook that the participants had immediately after the training session was not maintained for a longer period. Redmond and Griffith (25) mentioned that targeted food safety interventions could result in short-term improvements in consumer food safety behaviors. These improvements could be due to the lack of strong attitudes among participants but also could be due to persuasion appeal or the halo effect, where attitude change is observed "immediately after message presentation" $(20,25)$. These statements reflect what the results of the present study indicate: immediately after the information was presented in the training session, the positivity of the responses increased.

\section{CONCLUSION}

Results of the needs assessment indicated that the food safety training program should focus on Iowa state laws directed toward exempt home food operations and home bakeries in Iowa and on food safety basics and the unique food safety implications of the residential kitchen. The program evaluation based on attitude revealed that although some significant differences were found in participants responses between groups and among all participants immediately after the training session, many of the changes were not long term across many of the constructs. Educators and researchers should aim to increase scores for the positive 
behaviors, intentions, attitudes, perceived behavioral control, and social norms not only immediately after the training session but over time through altering the training program to focus more on behavioral and attitude changes. Participants did have overwhelmingly positive views of all constructs throughout all evaluations, but observational data may be needed to determine whether the participants' positive views carry over into positive food safety actions.

\section{ACKNOWLEDGMENTS}

The authors thank Arlene Enderton and Alice Topaloff (Iowa State University Extension and Outreach, Local Food Team) for their help with the development and implementation of the needs assessment and their assistance with managing the survey and using the Qualtrics software. The authors also thank Dr. Catherine Strohbehn, Barb Fuller, and Jill Weber (Iowa State University Extension and Outreach), Dr. Kathleen Hunt ( Department of Agriculture Education \& Studies, Iowa State University), and Julie Kraling (Iowa Department of Inspections and Appeals) for reviewing the training materials and providing feedback. Funding for this project was provided by an Iowa State University Extension and Outreach Excellence in Extension Herb Howell grant.

\section{REFERENCES}

1. Ajzen, I. 1991. The theory of planned behavior. Organ. Behav. Hum. Decis. Process. 50:179-211.

2. Byrd-Bredbenner, C., J. Berning, J. MartinBiggers, and V. Quick. 2013. Food safety in home kitchens: a synthesis of the literature. Int. J. Environ. Res. Public Health 10:40604085.

3. Byrd-Bredbenner, C., J. Maurer, V. Wheatley, D. Schaffner, C. Bruhn, and L. Blalock. 2007. Food safety self-reported behaviors and cognitions of young adults: results of a national study. J. Food Prot. 70:1917-1926.

4. Centers for Disease Control and Prevention. 2018. Outbreak of Salmonella infections linked to Gravel Ridge Farms shell eggsfinal update. Available at: https://www.cdc. gov/salmonella/enteritidis-09-18/index. html. Accessed 11 November 2020.

5. Centers for Disease Control and Prevention. 2019. Outbreak investigation of E. coli: flour (May 2019). Available at: https://www.fda. gov/food/outbreaks-foodborne-illness/ outbreak-investigation-e-coli-flour-may-2019. Accessed 11 November 2020.

6. Centers for Disease Control and Prevention. 2019. Outbreak of E. coli infections linked to flour (final update). Available at: https:// www.cdc.gov/ecoli/2019/flour-05-19/index. html. Accessed 11 November 2020.

7. Crowe, S. J., L. Bottichio, L. N. Shade, B. M. Whitney, N. Corral, B. Melius, K. D. Arends, D. Donovan, J. Stone, K. Allen, J. Rosner, J. Beal, L. Whitlock, A. Blackstock, J. Wetherington, L. A. Newberry, M. N. Schroeder, D. Wagner, E. Trees, S. Viazis, M. E. Wise, and K. P. Neil. 2017. Shiga toxinproducing E. coli infections associated with flour. N. Engl. J. Med. 377:2036-2043.

8. Friedman, D. S., D. Heisey-Grove, F. Argyros, E. Berl, J. Nsubuga, T. Stiles, J. Fontana, R. S. Beard, S. Monroe, M. E. McGrath, H. Sutherby, R. C. Dicker, A. DeMaria, and B. T. Matyas. 2005. An outbreak of norovirus gastroenteritis associated with wedding cakes. Epidemiol. Infect. 133:1057-1063.

9. Garayoa, R., M. Córdoba, I. García-Jalón, A. Sanchez-Villegas, and A. I. Vitas. 2005. Relationship between consumer food safety knowledge and reported behavior among students from health sciences in one region of Spain. J. Food Prot. 68:2631-2636.
10. Gilman, L. 2018. Development and assessment of a pilot food safety training for exempt home food operations and home bakeries in Iowa. Available at: https://lib. dr.iastate.edu/etd/17191/. Accessed 19 September 2020.

11. Harrison, J. A., F. J. Critzer, and M. A. Harrison. 2016. Regulatory and food safety knowledge gaps associated with small and very small food businesses as identified by regulators and food safety educatorsimplications for food safety training. Food Prot. Trends 36:420-427.

12. Harrison, J. A., J. W. Gaskin, M. A. Harrison, J. L. Cannon, R. R. Boyer, and G. W. Zehnder. 2013. Survey of food safety practices on small to medium-sized farms and in farmers markets. J. Food Prot. 6:1989-1993.

13. Iowa Department of Agriculture and Land Stewardship. 2020. Horticulture and farmers markets. Available at: https://iowaagriculture.gov/agriculturaldiversification-market-developmentbureau/horticulture-and-farmersmarkets\#: :text=Some 200 farmers markets in, $\% 2 \mathrm{C}$ wine $\% 2 \mathrm{C}$ cheese and crafts. Accessed 11 November 2020.

14. Iowa Department of Inspections and Appeals. 2018. Farmers markets requirements from inspections and appeals food and consumer safety bureau. Available at: https://web-dfsr. s3-fips-us-gov-west-1.amazonaws.com/ Iowa/assets/File/Farmers Market Food Requirements.pdf. Accessed 27 August 2018.

15. Iowa Department of Inspections and Appeals. 2019. Summary: home bakery. Available at: https://web-dfsr.s3-fips-us-gov-west-1. amazonaws.com/Iowa/assets/File/Iowa Code Chapter 137D Home Bakeries.pdf. Accessed 27 August 2018.

16. Iowa Food Safety and Protection Taskforce. 2017. Home based food operations. Available at: https://ia.foodprotectiontaskforce.com/ resources1/home-based-food-operations/ DesMoines Iowa. Accessed 28 August 2018.

17. Iowa State University Center for Excellence in Learning and Teaching. 2001. Revised Bloom's taxonomy-CELT. Available at: http://www.celt.iastate.edu/teaching/ effective-teaching-practices/revised-bloomstaxonomy. Accessed 14 September 2018.
18. Jevšnik, M., V. Hlebec, and P. Raspor. 2008. Consumers' awareness of food safety from shopping to eating. Food Control 19:737-745.

19. Laidler, M. R., M. Tourdjman, G. L. Buser, T. Hostetler, K. K. Repp, R. Leman, M. Samadpour, and W. E. Keene. 2013. Escherichia coli O157:H7 infections associated with consumption of locally grown strawberries contaminated by deer. Clin. Infect. Dis. 57:1129-1134.

20. Maio, G. R., and G. Haddock. 2015. The psychology of attitudes and attitude change, 2nd ed. Sage, London.

21. Milton, A. C., and B. A. Mullan. 2012. An application of the theory of planned behavior - a randomized controlled food safety pilot intervention for young adults. Health Psychol. 31:250-259.

22. Mohammad, Z. H., H. Yu, J. A. Neal, K. E. Gibson, and S. A. Sirsat. 2020. Food safety challenges and barriers in southern United States farmers markets. Foods 9(1):12.

23. Mullan, B. A., and C. L. Wong. 2009. Hygienic food handling behaviours. An application of the Theory of Planned Behaviour. Appetite 52:757-761.

24. Pilling, V. K., L. A. Brannon, C. W. Shanklin, K. R. Roberts, B. B. Barrett, and A. D. Howells. 2008. Food safety training requirements and food handlers' knowledge and behaviors. Food Prot. Trends 28:192-200.

25. Redmond, E. C., and C. J. Griffith. 2006. A pilot study to evaluate the effectiveness of a social marketing-based consumer food safety initiative using observation. Br. Food J. 108:753-770.

26. Roberts, K. R., and B. B. Barrett. 2011. Restaurant managers' beliefs about food safety training: an application of the Theory of Planned Behavior. J. Foodserv. Bus. Res. 14:206-225.

27. Scheinberg, J., R. Radhakrishna, and C. N. Cutter. 2013. Food safety knowledge, behavior, and attitudes of vendors of poultry products sold at Pennsylvania farmers' markets. J. Ext. 51:6FEA4.

28. Shapiro, M. A., N. Porticella, L. C. Jiang, and R. B. Gravani. 2011. Predicting intentions to adopt safe home food handling practices. Applying the Theory of Planned Behavior. Appetite 56:96-103. 
29. U.S. Department of Agriculture. 2014. New data reflects the continued demand for farmers markets. Available at: https://www. usda.gov/media/press-releases/2014/08/04/ new-data-reflects-continued-demandfarmers-markets. Accessed 28 August 2018.

30. U.S. Department Agriculture, Economic Research Service. 2016. Farmers' markets, other local food marketing channels show strong growth. Available at: https://www. ers.usda.gov/data-products/chart-gallery/ gallery/chart-detail/? chartId $=78076$. Accessed 11 November 2020.
31. Wisconsin Department of Health Services. 2017. Salmonella infections linked to shelled peas sold at three Wisconsin farmers markets. Available at: https://www.wisfarmer. com/story/news/state/2017/08/13/ salmonella-linked-shelled-peas-wi-farmersmarkets/563379001/. Accessed 6 September 2019.

32. Young, I., A. Thaivalappil, D. Reimer, and J. Greig. 2017. Food safety at farmers' markets: a knowledge synthesis of published research. J. Food Prot. 80:2033-2047.
33. Yu, H., K. E. Gibson, K. G. Wright, J. A. Neal, and S. A. Sirsat. 2017. Food safety and food quality perceptions of farmers' market consumers in the United States. Food Control 79:266-271.

\section{APPENDIX}

IOWASTATE UNIVERSTIV

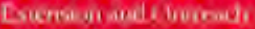
Agrouitran ame Raturas himaureat lowa State University Extension and Outreach (ISUEO) hired Dr. Shannon Coleman to provide education to home food operation owners. These are individuals who prepare foods to sell from their homes or at farmers' markets. Part of her work is to help them understand lowa's laws and regulations regarding sales and food safety practices for foods produced at home.

We invite you to take this survey to help ISUEO better understand your needs as a current or potential home food operation owner. The survey will take $\mathbf{5}$ to $\mathbf{1 0}$ minutes to complete, Your answers will be confidential, meaning we will report only aggregated results and will not share your individual answers. You may skip any question you do not want to answer. At the end of the survey we invite you to enter a drawing for $\mathbf{4}$, $\mathbf{2 5}$ gift cards. The contact information you share will not be linked to the answers you gave on the survey.

\section{Introductory questions}

1. Please choose the statement that best describes the stage of your Home Food Operation:

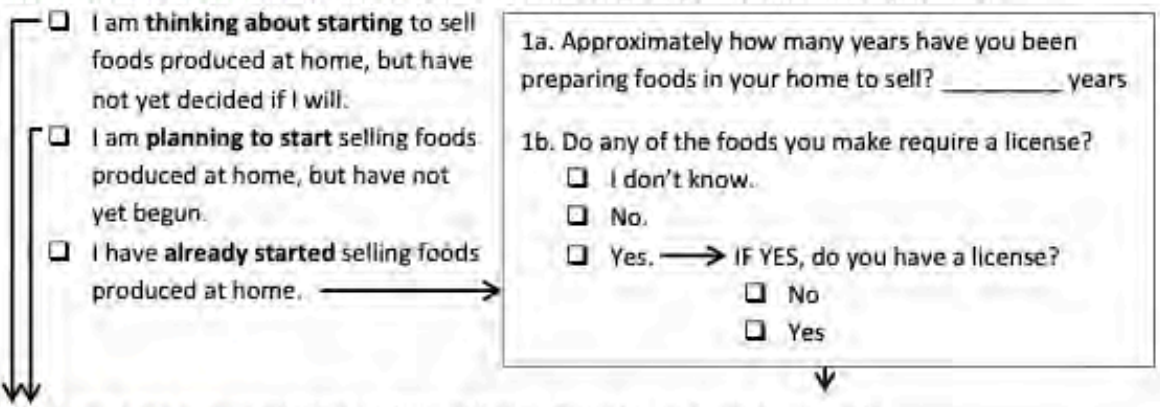

2. What foods are you considering making, planning to make, or already making?

What do you think? These questions help us measure your knowledge of food safety and related regulations.

3. Foods that need to be refrigerated should be kept at or below what temperature? (Please choose one.)

D $36^{\circ \mathrm{F}}$ or below
$41^{\prime \prime} \mathrm{F}$ or below
$\square .46^{\circ \mathrm{F}}$ or below

] $51^{\prime \prime} \mathrm{F}$ or below

a $56^{4} \mathrm{~F}$ or below

4. Please answer true or false for the following statements to the best of your ability:

\begin{tabular}{l} 
The following are all considered major aflergens; Peanuts, Soybeans, Milk, Eggs, Fish, \\
Shellfish, Tree Nuts, and Wheat. \\
To sell a refrigerated baked good, such as a cheesecake, at a farmers' market, the vendor \\
needs a food license and inspection. \\
Potentially hazardous food products are defined as foods that require temperature control. \\
Whole, uncut fruits and vegetables, baked goods (non-potentially hazardous), honey, fresh \\
whell eggs and other non-potentially hazardous foods can be sold at farmers' markets \\
she False \\
without a food license. \\
Only licensed vendors are required to display food allergen information on/near products. \\
\hline
\end{tabular}


5. Please rate how confident you feel regarding the following statements, where $1=1$ am sure I could NOT do it and $5=1$ am sure $I$ could do this. (Circle one answer in each line.)

\begin{tabular}{|c|c|c|c|c|c|c|}
\hline & $\begin{array}{l}1 \\
\text { I am sure I } \\
\text { could } \\
\text { NOT do it } \\
\end{array}$ & $\begin{array}{c}2 \\
\text { I could } \\
\text { not do } \\
\text { it }\end{array}$ & $\begin{array}{c}3 \\
\text { I do not } \\
\text { know if I } \\
\text { could do it }\end{array}$ & $\begin{array}{l}4 \\
\text { I could } \\
\text { do this }\end{array}$ & $\begin{array}{c}5 \\
\text { I am sure I } \\
\text { could do } \\
\text { this }\end{array}$ & $\begin{array}{c}\text { Not } \\
\text { Applicable }\end{array}$ \\
\hline $\begin{array}{l}\text { I can follow the laws and regulations } \\
\text { required by the State of lowa for my home } \\
\text { food operation. }\end{array}$ & 1 & 2 & 3 & 4 & 5 & N/A \\
\hline $\begin{array}{l}\text { I can label food products that I sell in } \\
\text { accordance with what is required by the } \\
\text { law. }\end{array}$ & 1 & 2 & 3 & 4 & 5 & N/A \\
\hline $\begin{array}{l}\text { I can accurately determine the shelf-life of } \\
\text { my product(s). }\end{array}$ & 1 & 2 & 3 & 4 & 5 & N/A \\
\hline $\begin{array}{l}\text { I can fill out the application and obtain } \\
\text { water tests to apply for a license for my } \\
\text { kitchen, if required. }\end{array}$ & 1 & 2 & 3 & 4 & 5 & N/A \\
\hline $\begin{array}{l}\text { I can arrange my point of sale in a way that } \\
\text { will protect the safety of foods I have made. }\end{array}$ & 1 & 2 & 3 & 4 & 5 & N/A \\
\hline
\end{tabular}

6. Food should be stored at least inches off the floor? (Please choose one answer.)

$\square 24^{\prime \prime}$
$\square 18^{\prime \prime}$
$\square 12^{\prime \prime}$

口 6"

None of the above; food does not have to be stored off the floor.

7. Proper hand washing procedures include using clean running warm water, soap, rubbing hands together for seconds, rinsing, and drying thoroughly. (Please select the correct answer to fill in the blank.)
- 5-10 seconds
20-25 seconds
a 10-15 seconds
- 25-30 seconds
- $15-20$ seconds

Food safety trainings

8. Which, if any, ISU Extension and Outreach food safety trainings have you taken? (Choose all that apply.)
口 ServSafe ${ }^{\text {ब }}$
- None
Farmers' Market Food Safety
Other (please specify)

Training

- Market Ready

Demographics The following information will help us determine if we are reaching a diversity of people.

9. What is your age? years

10. What is your ethnic background?

$$
\begin{aligned}
& \text { African American or Black } \\
& \text { Asian and Pacific American Islander } \\
& \text { Hispanic or Latino/a } \\
& \square \text { Multi-ethnic }
\end{aligned}
$$

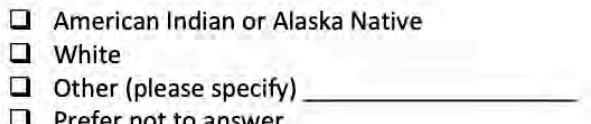

\section{Final Questions}

11. In the winter of 2017-18, Dr. Coleman will launch a pilot Home Food Qperation short course on food safety and Iowa's regulations regarding home food operations. Based on the outcomes of the pilot course, she will later launch a course open to everyone. Are you interested in participating in the pilot phase of the course?

Yes. IF YES, please provide your contact information below.

口 No.

12. Would you like to be entered into the drawing for one of the $4, \$ 25$ gitt cards?

Yes. If YES, please provide your contact information below.

Do.

Optional: Please share your name and contact information below. (If you share this information, we will protect your confidentiality by not sharing your individual answers to the survey. We will not share your contact information with anyone else.)

Name:

Email:

Phone: 